\title{
An object-based approach for semi-automated landslide change detection and attribution of changes to landslide classes in northern Taiwan
}

\author{
Daniel Hölbling $^{1} \cdot$ Barbara Friedl $^{1} \cdot$ Clemens Eisank $^{2}$
}

Received: 23 July 2014 / Accepted: 26 March 2015 / Published online: 7 April 2015

(C) The Author(s) 2015, corrected publication 2019

\begin{abstract}
Earth observation (EO) data are very useful for the detection of landslides after triggering events, especially if they occur in remote and hardly accessible terrain. To fully exploit the potential of the wide range of existing remote sensing data, innovative and reliable landslide (change) detection methods are needed. Recently, object-based image analysis (OBIA) has been employed for EO-based landslide (change) mapping. The proposed object-based approach has been tested for a sub-area of the Baichi catchment in northern Taiwan. The focus is on the mapping of landslides and debris flows/ sediment transport areas caused by the Typhoons Aere in 2004 and Matsa in 2005. For both events, pre- and post-disaster optical satellite images (SPOT-5 with $2.5 \mathrm{~m}$ spatial resolution) were analysed. A Digital Elevation Model (DEM) with $5 \mathrm{~m}$ spatial resolution and its derived products, i.e., slope and curvature, were additionally integrated in the analysis to support the semi-automated object-based landslide mapping. Changes were identified by comparing the normalised values of the Normalized Difference Vegetation Index (NDVI) and the Green Normalized Difference Vegetation Index (GNDVI) of segmentation-derived image objects between pre- and postevent images and attributed to landslide classes.
\end{abstract}

Communicated by: K. Nikolakopoulus

Published in the Special Issue of Remote Sensing and Geology "Surveying the GEOsphere"; with Guest Editors Dr. Konstantinos Nikolakopoulus, Dr. Cornelia Glaesser and Dr. Nilanchal Patel.

Daniel Hölbling

daniel.hoelbling@sbg.ac.at

1 Department of Geoinformatics - Z_GIS, University of Salzburg, Salzburg, Austria

2 GRID-IT Gesellschaft für angewandte Geoinformatik mbH, Innsbruck, Austria
Keywords Object-based image analysis (OBIA) •

Change detection $\cdot$ Landslide $\cdot$ Debris flow $\cdot$ Remote sensing

\section{Introduction}

Traditionally, pixel-based methods have been used for mapping changes based on high resolution (HR) or very high resolution (VHR) satellite imagery (Chen et al. 2012; Hussain et al. 2013). More recently, object-based image analysis (OBIA) has emerged as a new paradigm in the field of remote sensing (Blaschke et al. 2014a). OBIA has a high potential for accurate landslide delineation and change detection from satellite imagery (Blaschke et al. 2014b). By clustering individual pixels to differently sized image objects spectral, spatial, contextual and morphological characteristics can be addressed for the semi-automated recognition of landslide features. OBIA has demonstrated to be well applicable for the derivation of meaningful and detailed change information in a systematic and reproducible manner, especially in VHR images (Chen et al. 2012). The coupled analysis of pre- and post-event images allows for the detection of spectral and/or morphologic changes, which can be attributed to new and/or reactivated landslides (Borghuis et al. 2007; Mondini et al. 2011). Several studies have shown the applicability of OBIA for landslide mapping using knowledge-based, as well as statistical approaches (e.g., Martha et al. 2010; Lahousse et al. 2011; Stumpf and Kerle 2011; Hölbling et al. 2012; Blaschke et al. 2014b; Kurtz et al. 2014). However, only few studies have revealed the potential of OBIA for landslide change detection. Martha et al. (2012) suggested an approach based on brightness changes in pre- and post-event panchromatic images for the creation of historical landslide inventories. A semi-automatic object-oriented change detection approach using VHR optical satellite imagery for landslide rapid 
mapping was developed by $\mathrm{Lu}$ et al. (2011). Behling et al. (2014) proposed a method which combines pixel-based thresholds and object-based analysis for investigating temporal changes in NDVI-trajectories to identify landslide-related land cover changes based on RapidEye time series complemented by terrain information. Anders et al. (2013) used Light Detection and Ranging (LiDAR) digital terrain models for the analysis of geomorphological changes. Park and Chi (2008) proposed an unsupervised object-based change detection method to locate landslide-prone areas.

Yet many of the current approaches have limitations in situations where both fresh and older landslides are present in the analysed images, hindering the production of accurate event-based landslide inventories (Park and Chi 2008). Mondini et al. (2011) emphasized the added value of image analysis techniques that can distinguish new from old landslides and that also can map runout locations/debris flows, as this information is useful for disaster reduction and watershed management.

We present a semi-automated OBIA approach to tackle the above issues in landslide change detection based on SPOT-5 images and a Digital Elevation Model (DEM). The first aim was to detect landslides candidates and to classify them into "shallow landslides" and "debris flows/sediment transport areas" by considering spectral and morphological characteristics of segmentation-derived image objects. The second aim was the identification of class-specific changes by comparing the spectral properties of image objects in pre- and post-event images. The proposed OBIA approach for mapping typhoontriggered landslides and landslide changes was tested on a study site in Taiwan, which was affected by two major typhoon events in 2004 and 2005.

\section{Study area}

The proposed landslide mapping and change detection approach was tested for a sub-area of the Baichi catchment, which is located in the Shihmen Reservoir watershed in northern Taiwan (Fig. 1). The island of Taiwan is situated in the tropical and sub-tropical climate zones. During summer and autumn, especially from July to October, Taiwan is regularly affected by severe typhoons. The heavy rainfalls associated with these tropical storms often cause a large number of landslides and debris flows, leading to fatalities and vast damages of infrastructure (e.g., Rau et al. 2014). The study site covers an area of approximately $16 \mathrm{~km}^{2}$ and is characterised by densely vegetated mountainous terrain with steep slopes and highly fractured bedrocks. The catchment represents a typical landscape in Taiwan that is highly susceptible to landslides (see Fig. 2).

\section{Typhoon-induced landslides and debris flows in the Baichi catchment}

The focus of this study is the semi-automated (change) mapping of landslides and debris flows/sediment transport areas caused by the Typhoons Aere (August 23-26, 2004) and Matsa (August 3-6, 2005), respectively. After both typhoons an enormous increase in suspended sediment was observed in the downstream area of the Shihmen reservoir, causing severe problems such as the filling of storage reservoirs and logjams due to floating timber (Tsai et al. 2012).

Visual interpretation of post-event orthophotos revealed that Typhoon Aere caused 703 landslides in the Shihmen Reservoir watershed (Chang et al. 2008), whereof 421 landslides occurred in the Baichi catchment (Chang and Chiang 2009; Chiang and Chang 2009). Most of the observed slope failures in the Baichi catchment are shallow landslides that occur on slopes with a soil depth less than $2 \mathrm{~m}$ (Chang and Chiang 2009). Typhoon Aere brought more than $1600 \mathrm{~mm}$ and Typhoon Matsa over $1200 \mathrm{~mm}$ of accumulated rainfall to the Shihmen Reservoir watershed, whereby Baichi and Yufeng were the heaviest affected catchments (Chen et al. 2010).

\section{Methods}

\section{Datasets and pre-processing}

Pre- and post-event SPOT-5 images with three spectral bands (green, red, near infrared) and a spatial resolution of $2.5 \mathrm{~m}$ (panchromatic) and $10 \mathrm{~m}$ (multispectral) were available for the mapping of landslides and landslide changes. The SPOT-5 images illustrate the status quo before and after the Typhoons Aere and Matsa, respectively. After pansharpening in ERDAS IMAGINE® (Hexagon Geospatial) software with the Modified IHS Resolution Merge method (Siddiqui 2003) the images were co-registered to each other. Visual inspection after co-registration revealed that in a few areas shifts of about one pixel to two pixels occurred, which is due to the considerable differences in relief and the difficulty to find adequate control points in this natural landscape. Additionally, a DEM with $5 \mathrm{~m}$ spatial resolution and its derived products, i.e., slope and curvature, were integrated in the analysis to support the semi-automated classification of landslides and debris flows/sediment transport areas (see Table 1).

\section{Object-based classification based on post-event satellite imagery}

The proposed semi-automated object-based approach for the classification of landslides and debris flows/sediment transport areas was developed based on the post-event SPOT-5 image from 2005 and the $5 \mathrm{~m}$ DEM including its derivatives. 
Fig. 1 Study area in northern Taiwan: a overview of Taiwan with the Baichi catchment; b Baichi catchment and location of the study site within Baichi; c SPOT-5 image (acquisition date: 09/09/2005; after Typhoon Matsa) showing the study area; background data: (C) ESRI basemap data
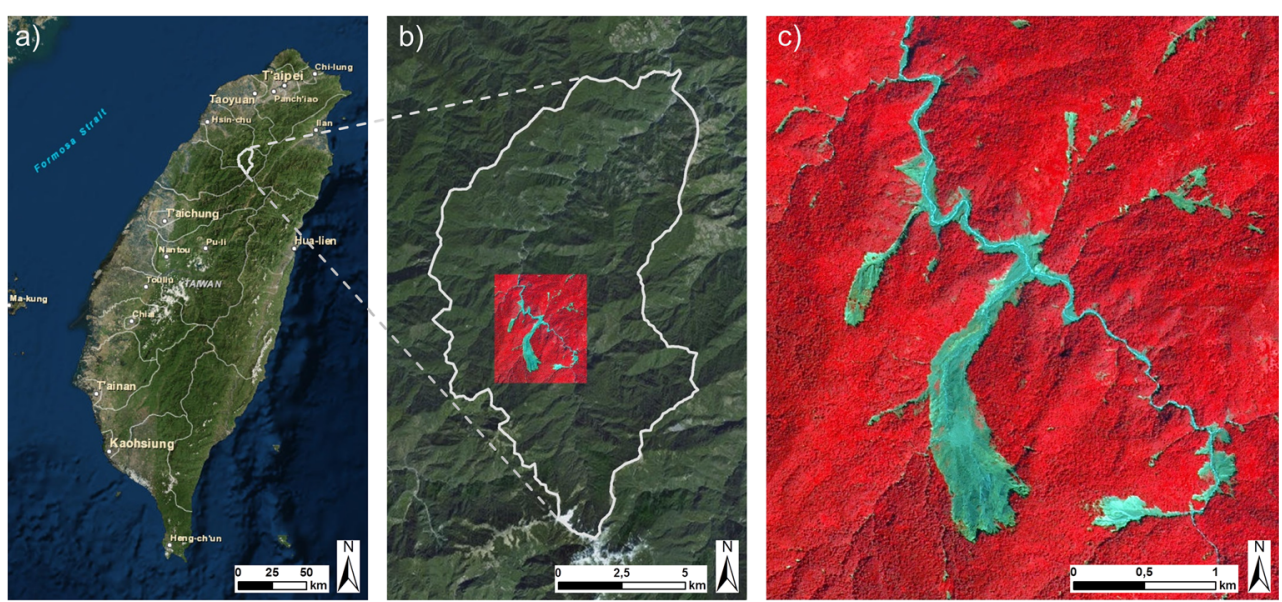

Image analysis was conducted in eCognition ${ }^{\circledR}$ (Trimble) software, defining a set of knowledge-based classification rules.

\section{Initial segmentation}

First, additional layers (Normalized Difference Vegetation Index - NDVI, Green Normalized Difference Vegetation Index - GNDVI, brightness) were calculated. The selection of an appropriate scale parameter for multiresolution segmentation was supported by the Estimation of Scale Parameter 2 (ESP 2) tool, which was implemented as customized algorithm in eCognition software. ESP 2 identifies statistically relevant image object levels for a set of input layers by evaluating the relative changes in local variance for user-defined scale ranges (Drăgut et al. 2014). A scale parameter of 32 was considered to be optimal for the combined segmentation of the three SPOT-5 bands, as well as the NDVI and brightness layer.

\section{Extraction of landslide candidates}

Landslide failures cause significant vegetation loss resulting in a distinct spectral contrast between landslides and their surroundings, supporting the detection of landslides in optical imagery (Behling et al. 2014). Such contrasts can especially be observed for event-based landslides occurring in densely vegetated regions such as Taiwan. The absence of vegetation and the presence of bare ground were assumed to be an indication of potential landslide areas. Therefore, low NDVI values of image objects, relative to the information contained in the image, were used to identify landslide-affected areas. The initial NDVI-based extraction of landslide candidates was slightly refined by using brightness in combination with context information. For instance, small shadow areas adjacent to landslide candidates were included in the classification. The extracted candidate areas were further divided into two classes: shallow landslides and debris flows/sediment transport areas.

\section{Landslide classification and class refinement}

Due to spectral similarity debris flows/sediment transport areas were mainly differentiated from shallow landslides by using morphological characteristics of image objects. An independent segmentation of plan curvature and slope with a
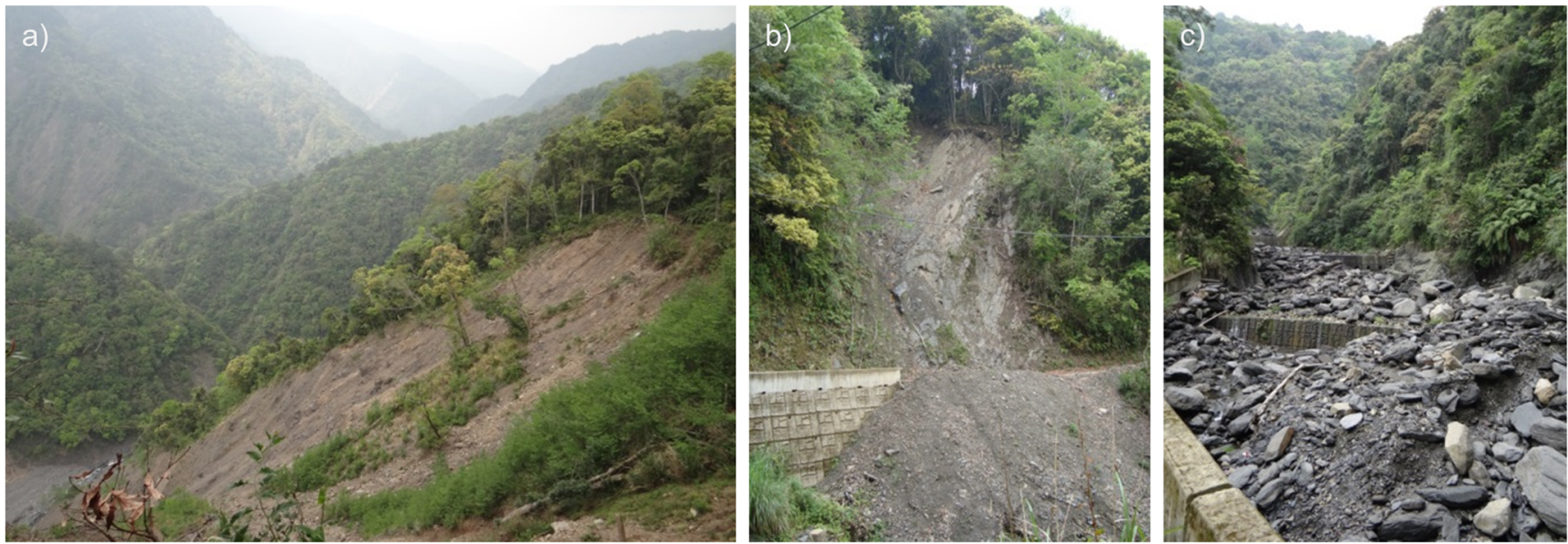

Fig. 2 Typical landslides ( $\mathrm{a}$ and $\mathrm{b}$ ) and debris flow/sediment transport area (c) in the Baichi catchment 
Table 1 Remote sensing data for the study area

\begin{tabular}{llll}
\hline Data & Description & Spatial resolution & Acquisition date \\
\hline SPOT-5 & Pre-event image: typhoon Aere & $2.5 \mathrm{~m}$ & $10 / 02 / 2004$ \\
& Post-event image: typhoon Aere & $2.5 \mathrm{~m}$ & $02 / 11 / 2004$ \\
& Pre-event image: typhoon Matsa & $2.5 \mathrm{~m}$ & $16 / 03 / 2005$ \\
& Post-event image: typhoon matsa & $2.5 \mathrm{~m}$ & $09 / 09 / 2005$ \\
\multirow{2}{*}{ DEM } & Pre-event data; including DEM & $5 \mathrm{~m}$ & Derived from orthophotos \\
& $\quad$ derivatives: slope, curvature, & & acquired in 2002 and \\
& plan curvature & & 2003 \\
\hline
\end{tabular}

scale parameter of 15 was performed within a sub-project in eCognition to facilitate the delineation of channel-like features where debris flows/sediment transport areas likely occur. Working with such sub-projects allows independent processing (e.g., segmentation, classification) for the same area. In the end, results can be merged while preserving the initial image object boundaries. First, objects with curvature values $<0$ were classified as concave terrain where sediment is most likely accumulated and transported downstream. Next, texture and context information of image objects were used to enhance the extraction of stream channels, particularly to remove several false positive objects fulfilling the curvature threshold. GLCM (Gray Level Co-occurrence Matrix) contrast of the slope layer, which measures the local variations in the GLCM, was applied to remove already classified objects with a GLCM contrast (all dir.) value < 0.15 . Directional GLCMs, especially the GLCM contrast between landslide areas and surrounding areas, appear to be very efficient in landslide detection (Blaschke et al. 2014b). The thresholds were selected based on visual assessment. Finally, small objects which were isolated, and thus, unconnected to channels were removed from the classification. The classified debris flows/sediment transport areas were then merged with the previously classified landslide candidates. Areas where both classes overlapped were further treated as debris flows/sediment transport areas. This procedure allowed classifying debris flows/sediment transport areas by considering spectral characteristics, as well as morphological characteristics derived from a spectrally independent segmentation based on DEM derivatives. It is noteworthy that the class debris flows/sediment transport areas also includes the river beds where the downstream transportation of debris and sediments occurs. The remaining landslide candidates were classified as shallow landslides. Subsequently, the two classes were iteratively refined by using spatial (e.g., area, shape) and contextual parameters (e.g., relative border to neighbouring objects) of image objects to eliminate false positives with spectral properties similar to landslide areas (e.g., cleared bamboo forests, paths, harvested agricultural fields). The boundaries of the classified image objects were finally smoothed with growing and shrinking operations.

\section{Testing the transferability of the classification approach}

The described approach (cf. Fig. 3) was transferred to the postevent SPOT-5 image from 2004, which showed radiometric differences compared to the image from 2005 (see Table 2). More shadows were present, and the vegetation appeared to be darker. Nevertheless, since the usage of absolute spectral thresholds was minimised, the developed OBIA classification approach could be transferred with only minor adaptations to the 2004 post-event image.

The two landslide classifications based on the 2004 and 2005 post-event images served as input for the class-specific landslide change detection as described in the following section.

\section{Object-based change detection}

The class-specific object-based change detection was initially accomplished for the Typhoon Matsa event (2005) and then transferred to the images available for the Typhoon Aere (2004). Fig. 3 gives an overview about the developed workflow for landslide classification and landslide change mapping.

\section{Multi-temporal image segmentation}

First, a joint multiresolution segmentation on the 2005 preand post-event images, denoted as "image pair", was performed using the three bands of the SPOT-5 images and the NDVI layers, in total eight bands. Such a multi-temporal object change detection approach produces spatially corresponding change objects, since temporally consecutive images are combined and segmented together (Chen et al. 2012). Again, the selection of an appropriate scale parameter, in this case 31 , was supported by the statistical evaluation with the ESP 2 tool. Each object of the segmentation result was then analysed with respect to its transformation between the pre- and post-event image.

\section{NDVI and GNDVI normalisation}

New landslides and debris flows/sediment transport areas were recognised by comparing NDVI and GNDVI values of 


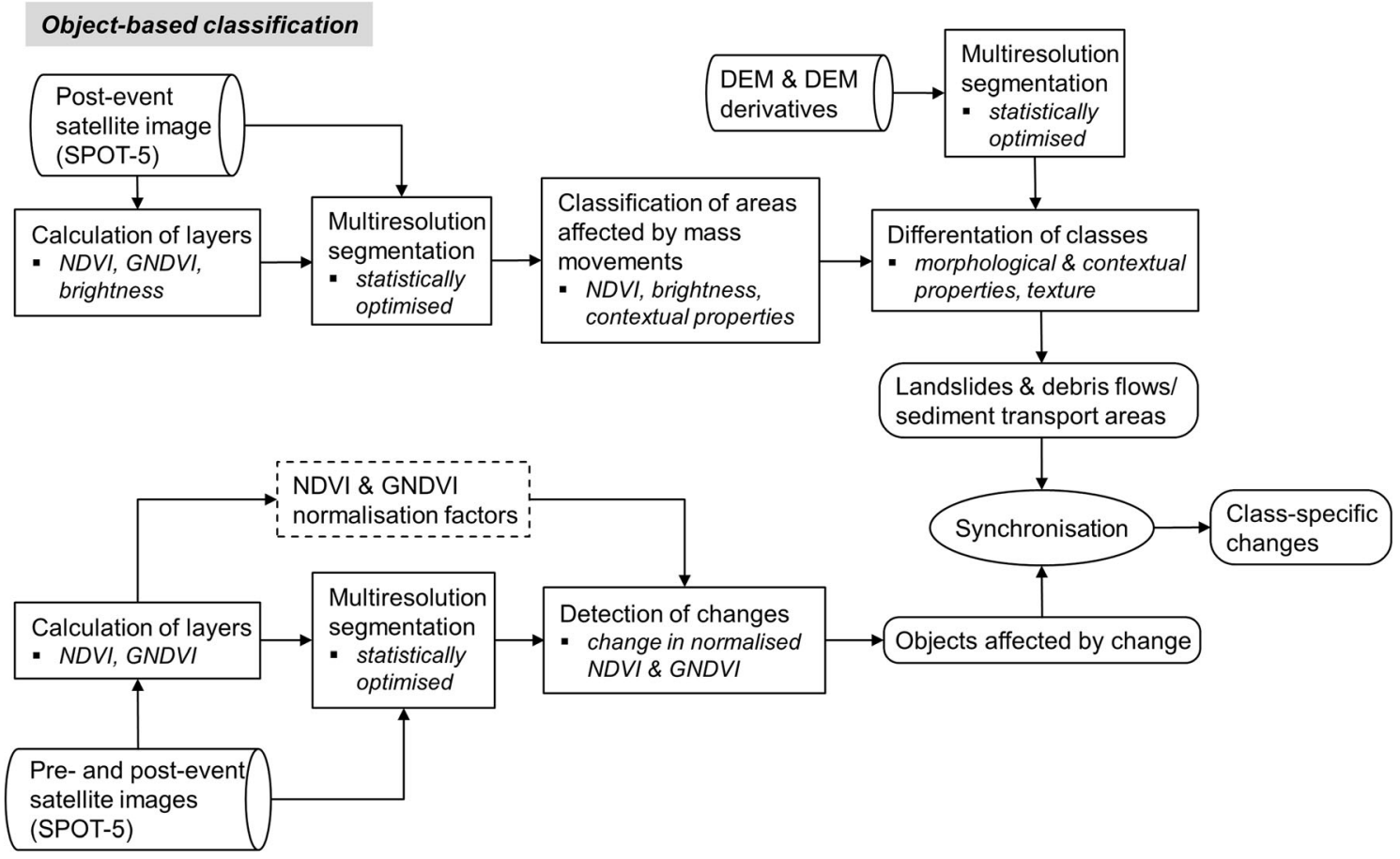

\section{Object-based change detection}

Fig. 3 Workflow for object-based landslide classification and change detection

segmentation-derived image objects between the corresponding pre- and post-event images. Vegetation loss was identified by a negative change of the NDVI and the GNDVI. As the radiometric characteristics between the image pairs slightly differed (different appearance of vegetation and shadows mainly because of different acquisition dates during the year; see Table 1), the comparison of the absolute NDVI and GNDVI values would have been biased. Therefore, the vegetation indices across the respective pre- and post-event images were normalised by using normalisation factors. The normalisation factors were calculated by dividing the mean value of the pixels of the post-event NDVI and GNDVI, respectively, by the value of the corresponding pre-event index. By multiplying the pre-event NDVI and GNDVI with the corresponding normalisation factor, the indices were calibrated to the radiometric characteristics of the post-event image. Consequently, the comparability of the pre- and post-event indices was increased.

\section{Change detection}

For each image object, the difference in the NDVI and GNDVI was calculated by subtracting the post-event value from the normalised pre-event value. For the NDVI, if the change was higher than a defined threshold of 0.5 , the objects were classified as affected by change. For the GNDVI, the change threshold was set to 0.4 . These thresholds were manually determined after visual assessment and used to prevent the classification of objects, which showed only minor value changes. In each case, a second condition was applied to detect only those objects with a relatively low NDVI or GNDVI value in terms of the relative information contained in the post-event image, i.e., objects with very little or no vegetation. Hence, areas which had been affected by a change in vegetation, but which were still vegetated, could be excluded. Most of the changes were recognized by applying the NDVI; the GNDVI allowed for the detection of several small-scale changes, which were not captured by the
Table 2 Comparison of mean pixel values and standard deviation of pixel values for postevent SPOT-5 images from 2004 and 2005

\begin{tabular}{llllll}
\hline \multirow{2}{*}{ Band } & \multicolumn{2}{l}{ Post-event SPOT-5 } & image from 2004 & & \multicolumn{2}{l}{ Post-event SPOT-5 image from 2005 } \\
\cline { 2 - 3 } & Mean value & Standard deviation & & Mean value & Standard deviation \\
\hline Green & 55.3 & 40.2 & & 32.6 & 35.3 \\
Red & 31.7 & 41.8 & & 29.5 & 40.2 \\
Near Infrared & 151.8 & 55.8 & & 159.8 & 53.3 \\
\hline
\end{tabular}


NDVI. Finally, the objects affected by change were synchronised, i.e., merged, with the prior established classification of shallow landslides and debris flow/sediment transport areas, and thus, changes were attributed to landslide classes. Small sliver polygons resulting from the synchronisation were removed by applying object growing and shrinking algorithms. The same procedure was applied for detecting the changes caused by Typhoon Aere, whereby no adaptations in the ruleset were necessary.

\section{Results}

Figure 4 shows the results of the semi-automated object-based classification of shallow landslides and debris flows/sediment transport areas for the post-event SPOT-5 images from 2004 and 2005.

For a quantitative assessment of the classification accuracy, both classification results were compared to respective landslide inventories that were produced by local landslide experts through visual interpretation of post-event orthophotos with $0.5 \mathrm{~m}$ spatial resolution. It is important to note that the orthophotos were acquired at similar times as the post-event SPOT-5 images; thus, representing the same state of the environment. As the reference data set excluded debris flows or other sediment transport areas, only the accuracy of the detected landslides was assessed (see Table 3). In general, the semi-automated classification overestimates the reference; the deviation between the semi-automatically classified landslides and the reference accounts to approximately $20 \%$ for 2004 and about $24 \%$ for 2005 .
A qualitative assessment of the classification results was conducted together with Taiwanese landslide experts, who confirmed the validity of the results during recent workshops and personnel discussions. However, this expert assessment revealed that especially the differentiation of landslides and debris flows needs further attention (see Discussion section).

The results of the class-specific change detection (Fig. 5) revealed that about $58.5 \%$ of areas affected by landslides and $36.5 \%$ of the debris flows/sediment transport areas detected in the post-event image of 2004 were caused by Typhoon Aere. Approximately $10 \%$ of areas affected by landslides and $5.5 \%$ of the debris flows/sediment transport areas detected in the post-event image of 2005 were caused by Typhoon Matsa.

\section{Discussion}

For semi-automated detection and classification of landslide changes, optimal data bases should include cloud and shadowfree pre-and post-event optical images, which are ideally acquired just before and after an event. In addition, accurate pre- and post-event DEM data should complement the data basis. However, in practice, such a data base is rarely available, especially if rapid information delivery after landslide triggering events is required. The proposed approach therefore represents a realistic showcase regarding data availability. It can be assumed that the achieved mapping accuracies are lower than for the "perfect" situation.
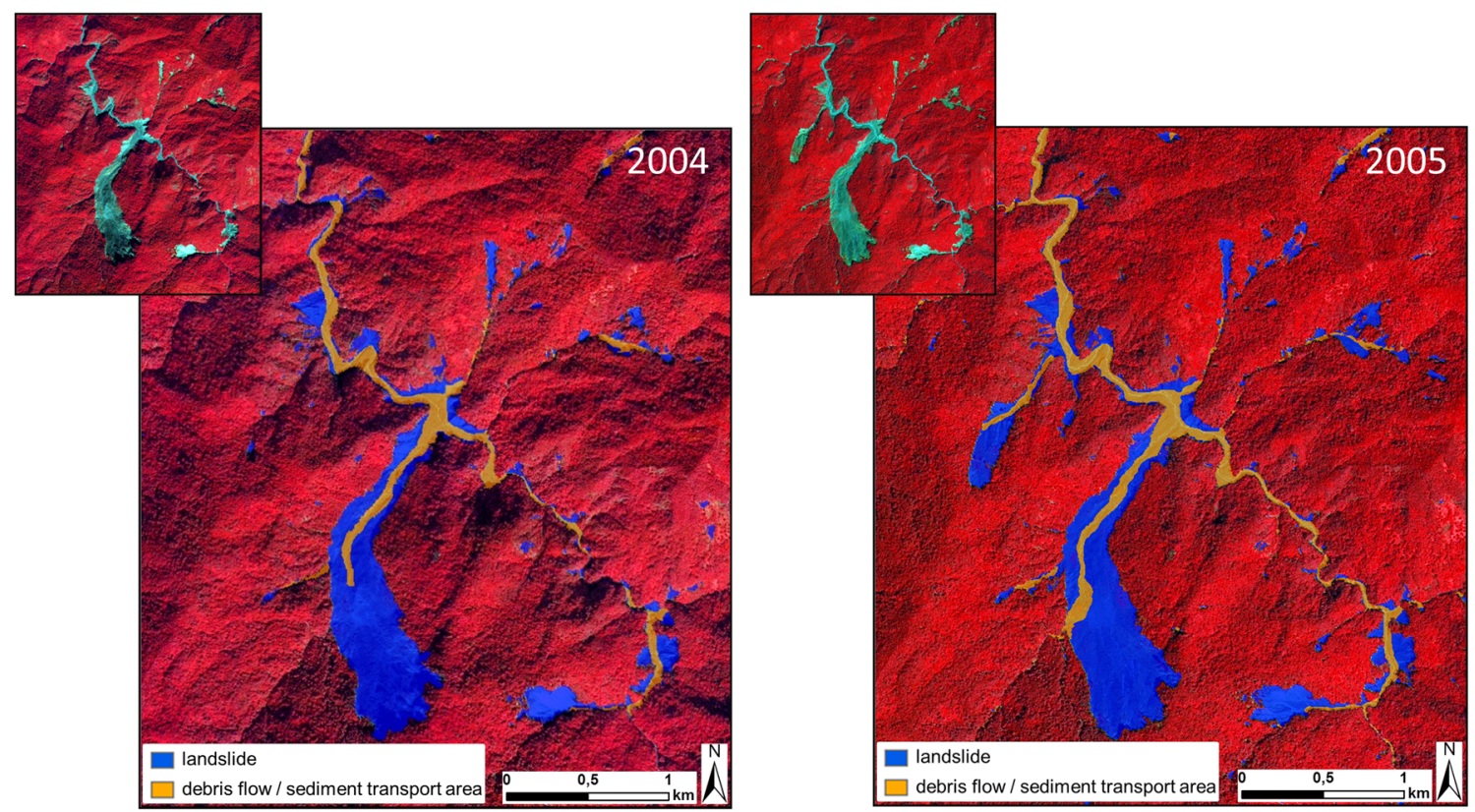

Fig. 4 Classification result showing the detected landslides and debris flows/sediment transport areas after Typhoon Aere (2004; left) and after Typhoon Matsa $(2005 ;$ right $)$ 
Table 3 Classification results (in hectare) for the post-event images from 2004 and 2005 and producer's and user's accuracy for the class "shallow landslides"

\begin{tabular}{|c|c|c|c|c|c|c|}
\hline & Class & $\begin{array}{l}\text { Classification } \\
\text { (in ha) }\end{array}$ & $\begin{array}{l}\text { Reference } \\
\text { (in ha) }\end{array}$ & $\begin{array}{l}\text { Correctly classified } \\
\text { areas (in ha) }\end{array}$ & $\begin{array}{l}\text { Producer's accuracy } \\
\text { (in \%) }\end{array}$ & $\begin{array}{l}\text { User's accuracy } \\
\text { (in \%) }\end{array}$ \\
\hline \multirow[t]{2}{*}{ Aere (2004) } & Shallow landslides & 96.42 & 80.08 & 68.04 & 84.97 & 70.57 \\
\hline & $\begin{array}{l}\text { Debris flows/ sediment } \\
\text { transport areas }\end{array}$ & 34.67 & $\mathrm{n} / \mathrm{a}$ & $\mathrm{n} / \mathrm{a}$ & $\mathrm{n} / \mathrm{a}$ & $\mathrm{n} / \mathrm{a}$ \\
\hline \multirow[t]{2}{*}{ Matsa (2005) } & Shallow landslides & 112.57 & 90.6 & 76.28 & 84.19 & 67.76 \\
\hline & $\begin{array}{l}\text { Debris flows/ sediment } \\
\text { transport areas }\end{array}$ & 49.01 & $\mathrm{n} / \mathrm{a}$ & $\mathrm{n} / \mathrm{a}$ & $\mathrm{n} / \mathrm{a}$ & $\mathrm{n} / \mathrm{a}$ \\
\hline
\end{tabular}

\section{Change detection by means of spectral indices}

Changes were identified by comparing the normalised values of the NDVI and the GNDVI of image objects between preand post-event images. The use of such indices can minimise the topographic effects and differences in reflectance when working with multi-temporal images (Singh 1989). Chen et al. (2012) pointed out that the normalisation of band intensities of multi-temporal imagery to a reference scene is sufficient for many change detection applications. Thus, this strategy was followed instead of complicated radiometric correction, which does not necessarily lead to significantly improved change detection accuracy (Song et al. 2001; Chen et al. 2012). Decision on whether atmospheric and radiometric corrections are performed depends on the information to be extracted and on the analytical methods used to obtain the desired information (Song et al. 2001) and to some degree also on the remote sensing data used (Singh 1989). The use of image objects reduces the effects of radiometrically and atmospherically not perfectly corrected pixel values. Therefore, the usually critical task of atmospheric and radiometric image correction is assumed not to be as important for object-based change detection as for pixel-based change detection.

\section{Differentiation of landslides and debris flows}

Further research is needed to improve the differentiation of landslides and debris flows/sediment transport areas based on remote sensing data. Similar conclusions were drawn by Mondini et al. (2011). Although debris flows pose a severe

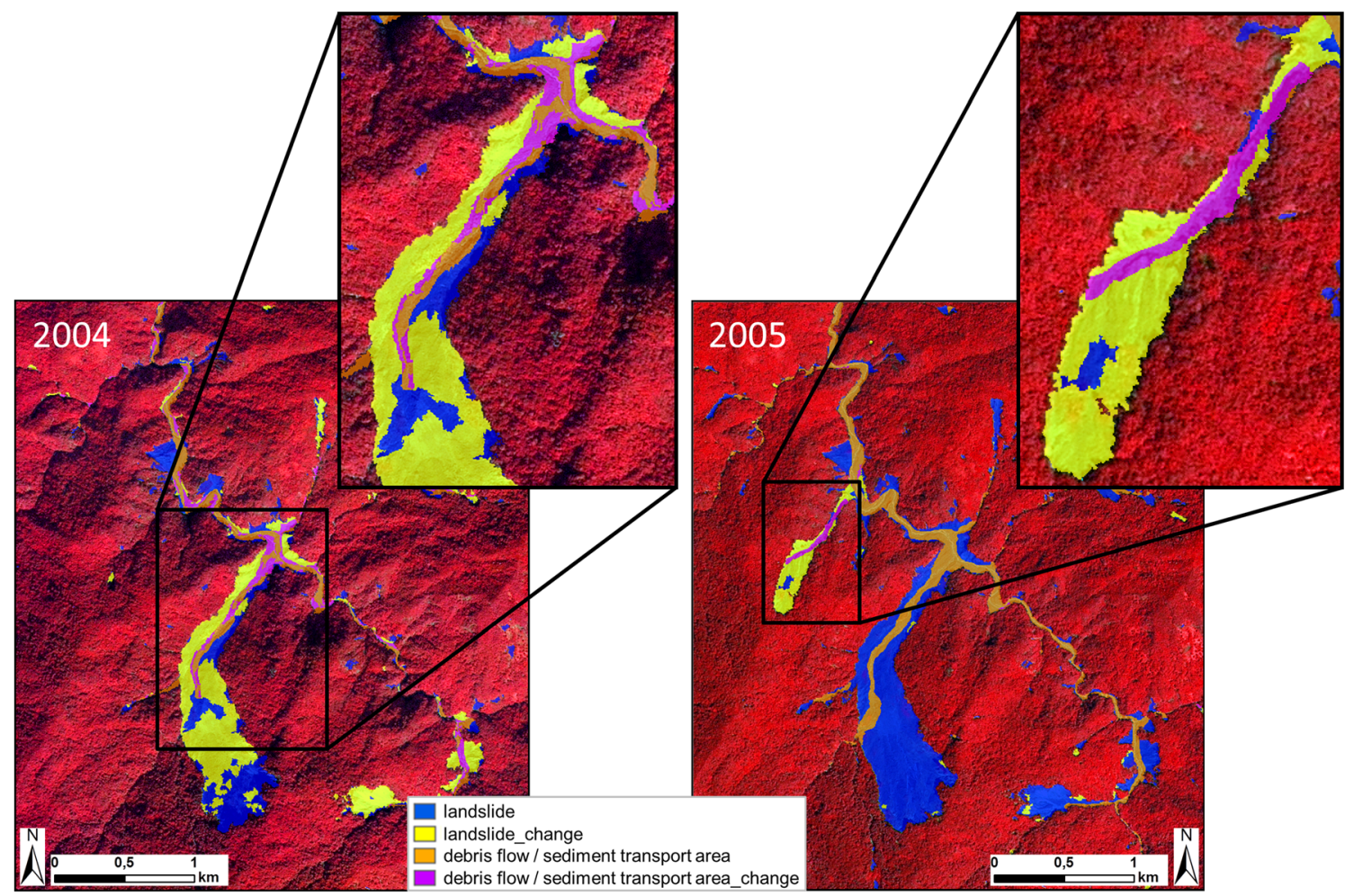

Fig. 5 Results of the class-specific object-based change detection for 2004 (left) and 2005 (right). Pre- and post-typhoon landslides (in blue and yellow, respectively) and debris flows/sediment transport areas (in orange and purple, respectively) are shown 

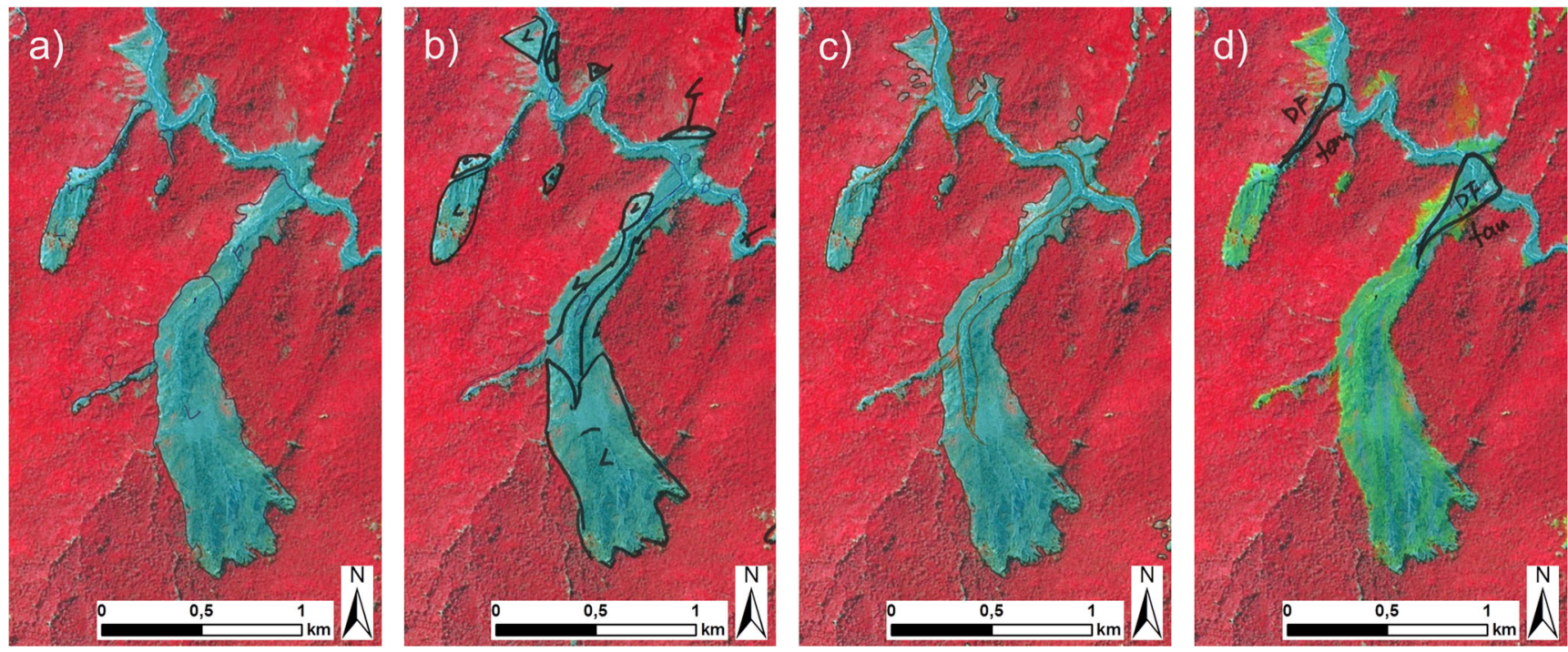

Fig. 6 Four illustrative examples of manual delineations of landslides and debris flows performed by Taiwanese landslide experts based on the postevent SPOT-5 image from 2005

threat in Taiwan - they often cause more serious damages than landslides - comprehensive mapping efforts or data bases comprising debris flows are still missing. The reason for that may lie in the fact that it is hardly possible to find generally valid properties to describe this type of mass movement. For tackling this problem we developed an object-based method to classify debris flows including additional areas where sediment transport takes place, i.e., river beds. The class differentiation mainly relies on morphological properties; however, this causes other difficulties. The available DEMs are usually outdated and older than the used satellite image. In this study, the DEM was derived from orthophotos taken in 2002 and 2003, which means that the topographic signatures of the numerous landslides that occurred in 2004 and 2005 are not represented by the data. The integration of accurate and high resolution pre- and post-event DEMs, e.g., derived from LiDAR acquisitions, could probably improve the results. Due to data restrictions an up-to-date highresolution DEM was not at hand for this study.

The detected landslides in the post-event images from 2004 and 2005 were validated by comparing them to manually derived landslide maps. Such data sets are often the only reference available, but cannot constitute a completely true reference (Hölbling et al. 2012) as their generation depends on the skills of the interpreter, the underlying data, on the mapping scale, and on the purpose of the manual mapping. This fact has to be considered when interpreting the accuracy values. For future studies it will be necessary to get reliable reference data for debris flows, as well as to conduct a comprehensive validation of the results. However, this is difficult to achieve, since a common understanding among Taiwanese landslide experts on how debris flows in Taiwan can be conceptually and operationally distinguished from landslides is still missing. This was emphatically confirmed by Taiwanese experts during personnel semistructured interviews and during several field trips with
Taiwanese colleagues in the past years. In the frame of a dedicated workshop on digital landslide mapping in spring 2014 we asked Taiwanese experts to manually delineate and differentiate landslides and debris flows on hard copies of the SPOT-5 images used in this study. The results were highly heterogeneous and revealed the ambiguity in differentiating landslides and debris flows. Figure 6 shows selected examples of the manual delineation on the post-event SPOT-5 image from 2005.

To further improve the objectivity, transferability and robustness of the method the common knowledge of a number of experts should be transformed into computer-based rules and integrated in the analysis. Such a knowledge-based landslide mapping system was recently proposed by Eisank et al. (2014). Moreover, future work should encompass the application of the proposed approach in other and larger study areas with different geo-environmental conditions as well as using satellite imagery from other sensors to further assess, evaluate and improve its transferability.

\section{Conclusions}

In this study we proposed an object-based approach for landslide and debris flow classification and landslide change mapping in northern Taiwan. Landslides and debris flows/sediment transport areas triggered by two major typhoons, Aere and Matsa, were mainly differentiated based on morphological properties. The changes were identified by comparing feature values of segmentation-derived image objects between pre-and post-event SPOT-5 images. Instead of using absolute spectral characteristics, changes were mainly recognised based on the relative difference of normalised NDVI and GNDVI.

Semi-automated object-based change detection approaches can, for example, be used for the regular update of landslide 
inventory maps after major events or may be useful as initial input for manual mapping. Such a hybrid mapping workflow, i.e., indicating affected areas by applying a semi-automated analysis first and then using this initial result for manual refinement, might reduce the operating time and costs as compared to mere manual mapping efforts. Furthermore, areas potentially susceptible to landslides may be identified by retrospective analyses of past landslide events. Results might be of interest for local stakeholders and decision makers, as information on the location and spatial distribution of both new and reactivated landslides can be beneficial for future landslide risk assessment.

Acknowledgments This research is supported by the Austrian Science Fund through the project "'iSLIDE - Integrated Semi-Automated Landslide Delineation, Classification and Evaluation" (FWF-P25446-N29). The authors would like to thank Yi-Chin Chen and Kang-Tsung Chang for providing the reference data as well as Antonia Osberger for fruitful discussions and valuable comments. We also want to thank the Taiwanese colleagues and experts who supported this research with data pre-processing, as well as participation in the workshop, interviews and field trips.

Open Access This article is distributed under the terms of the Creative Commons Attribution 4.0 International License (http:// creativecommons.org/licenses/by/4.0/), which permits use, duplication, adaptation, distribution and reproduction in any medium or format, as long as you give appropriate credit to the original author(s) and the source, provide a link to the Creative Commons license, and indicate if changes were made.

\section{References}

Anders N, Seijmonsbergen A, Bouten W (2013) Geomorphological change detection using object-based feature extraction from multitemporal lidar data. IEEE Geosci Remote Sens Lett 10:1587-1591. doi:10.1109/LGRS.2013.2262317

Behling R, Roessner S, Kaufmann H, Kleinschmit B (2014) Automated spatiotemporal landslide mapping over large areas using rapideye time series data. Remote Sens 6:8026-8055. doi:10.3390/rs6098026

Blaschke T, Hay GJ, Kelly M, Lang S, Hofmann P, Addink E, Feitosa RQ, van der Meer F, van der Werff H, van Coillie F, Tiede D (2014a) Geographic object-based image analysis - towards a new paradigm. ISPRS J Photogramm 87:180-191. doi:10.1016/j.isprsjprs.2013.09.014

Blaschke T, Feizizadeh B, Hölbling D (2014b) Object-based image analysis and digital terrain analysis for locating landslides in the Urmia Lake Basin, Iran. IEEE J Sel Top Appl 7:4806-4817. doi:10.1109/ JSTARS.2014.2350036

Borghuis A, Chang K, Lee H (2007) Comparison between automated and manual mapping of typhoon-triggered landslides from SPOT-5 imagery. Int J Remote Sens 28:1843-1856. doi:10.1080/01431160600935638

Chang KT, Chiang SH (2009) An integrated model for predicting rainfallinduced landslides. Geomorphology 105:366-373. doi:10.1016/j. geomorph.2008.10.012

Chang KT, Chiang SH, Lei F (2008) Analysing the relationship between typhoon-triggered landslides and critical rainfall conditions. Earth Surf Process Landforms 33:1261-1271. doi:10.1002/esp.1611

Chen CY, Chen LK, Yu FC, Lin SC, Lin YC, Lee CL, Wang YT (2010) Landslides affecting sedimentary characteristics of reservoir basin. Environ Earth Sci 59:1693-1702. doi:10.1007/s12665-009-0151-0

Chen G, Hay GJ, Carvalho L, Wulder MA (2012) Object-based change detection. Int J Remote Sens 33:4434 4457. doi:10.1080/01431161. 2011.648285
Chiang SH, Chang KT (2009) Application of radar data to modeling rainfall-induced landslides. Geomorphology 103:299-309. doi:10. 1016/j.geomorph.2008.10.012

Drăguț L, Csillik O, Eisank C, Tiede D (2014) Automated parameterisation for multi-scale image segmentation on multiple layers. ISPRS J Photogramm Remote Sens 88:119-127. doi:10.1016/j.isprsjprs.2013.11.018

Eisank C, Hölbling D, Friedl B, Chen YC, Chang KT (2014) Expert knowledge for object-based landslide mapping in Taiwan. S East Eur J Earth Obs Geomat Spec Issue: GEOBIA 2014 Adv Trends Challenges Geogr Object-Based Image Anal Conf 3:347-350

Hölbling D, Füreder P, Antolini F, Cigna F, Casagli N, Lang S (2012) A semi-automated object-based approach for landslide detection validated by persistent scatterer interferometry measures and landslide inventories. Remote Sens 4:1310-1336. doi:10.3390/rs4051310

Hussain M, Chen D, Cheng A, Wei H, Stanley D (2013) Change detection from remotely sensed images: from pixel-based to object-based approaches. ISPRS J Photogramm Remote Sens 80:91-106. doi:10. 1016/j.isprsjprs.2013.03.006

Kurtz C, Stumpf A, Malet JP, Gançarski P, Puissant A, Passat N (2014) Hierarchical extraction of landslides from multiresolution remotely sensed optical images. ISPRS J Photogramm 87:122-136. doi:10. 1016/j.isprsjprs.2013.11.003

Lahousse T, Chang K-T, Lin Y (2011) Landslide mapping with multiscale object-based image analysis - a case study in the Baichi watershed, Taiwan. Nat Hazards Earth Syst Sci 11:2715-2726. doi:10. 5194/nhess-11-2715-2011

Lu P, Stumpf A, Kerle N, Casagli N (2011) Object-oriented change detection for landslide rapid mapping. IEEE Geosci Remote Sens Lett 8:701-705. doi:10.1109/LGRS.2010.2101045

Martha TR, Kerle N, Jetten V, van Westen CJ, Kumar KV (2010) Characterising spectral, spatial and morphometric properties of landslides for semi-automatic detection using object-oriented methods. Geomorphology 116:24-36. doi:10.1016/j.geomorph.2009.10.004

Martha TR, Kerle N, van Westen CJ, Jetten V, Kumar KV (2012) Objectoriented analysis of multi-temporal panchromatic images for creation of historical landslide inventories. ISPRS J Photogramm Remote Sens 67:105-119. doi:10.1016/j.isprsjprs.2011.11.004

Mondini AC, Chang K-T, Yin H-Y (2011) Combining multiple change detection indices for mapping landslides triggered by typhoons. Geomorphology 134:440-451. doi:10.1016/j.geomorph.2011.07.021

Park NW, Chi KH (2008) Quantitative assessment of landslide susceptibility using high-resolution remote sensing data and a generalized additive model. Int J Remote Sens 29:247-264. doi:10.1080/ 01431160701227661

Rau JY, Jhan JP, Rau RJ (2014) Semiautomatic object-oriented landslide recognition scheme from multisensor optical imagery and DEM. IEEE Trans Geosci Remote Sens 52:1336-1349. doi:10.1109/ TGRS.2013.2250293

Siddiqui Y (2003) The modified ihs method for fusing satellite imagery. Proc. ASPRS Annual Conf. 5-9, Anchorage, Alaska

Singh A (1989) Digital change detection techniques using remotelysensed data. Int J Remote Sens 10:898-1003. doi:10.1080/ 01431168908903939

Song C, Woodcock CE, Seto KC, Lenney MP, Macomber SA (2001) Classification and change detection using Landsat TM data: when and how to correct atmospheric effect? Remote Sens Environ 75: 230-244. doi:10.1016/S0034-4257(00)00169-3

Stumpf A, Kerle N (2011) Object-oriented mapping of landslides using Random Forests. Remote Sens Environ 115:2564-2577. doi:10. 1016/j.rse.2011.05.013

Tsai ZX, You GJY, Lee HY, Chiu YJ (2012) Use of a total station to monitor post-failure sediment yields in landslide sites of the Shihmen reservoir watershed, Taiwan. Geomorphology 139-140: 438-451. doi:10.1016/j.geomorph.2011.11.008 